\title{
Demecolcine-induced enucleation of sheep meiotically maturing oocytes
}

\author{
Jian Hou, Tinghua LeI, Lei LIU, Xiuhong CUI, Xiaorong AN*, \\ Yongfu CHEN
}

State Key Laboratory for Agrobiotechnology and Department of Animal Physiology, College of Biological Science, China Agricultural University, Beijing, 100094, China

(Received 02 March 2005; accepted 15 November 2005)

\begin{abstract}
The objective of this study was to investigate the possible effect of demecolcine, a microtubule-disrupting reagent, on induced enucleation (IE) of sheep meiotically maturing oocytes. Immunofluorescent staining with anti-tubulin antibodies was used to examine the spindle status of the oocytes. When the oocytes with intact germinal vesicles $(\mathrm{GV})$ were cultured in the medium containing various concentrations of demecolcine $\left(0.01\right.$ to $\left.0.4 \mu \mathrm{g} \cdot \mathrm{mL}^{-1}\right)$ for 20 to $22 \mathrm{~h}$, the spindle microtubule organization and first polar body (PB1) extrusion were inhibited by demecolcine in a dose-dependent manner. The highest IE rate $(58.1 \%)$ was from the treatment with $0.04 \mu \mathrm{g} \cdot \mathrm{mL}^{-1}$ demecolcine. Demecolcine treatment applied after germinal vesicle breakdown (GVBD) or at metaphase (M) yielded a PB1 extrusion rate and IE efficiency similar to the treatment applied at the onset of maturation. Analysis by immunofluorescence showed that both nonspindle microtubules and spindle microtubules were significantly disorganized by demecolcine. Combination treatment with demecolcine and cycloheximide (CHX) or 6-dimethylaminopurine (6-DMAP) led to single pronuclear formation rather than $\mathrm{PB} 1$ extrusion. When demecolcine-treated oocytes were transferred into demecolcine-free medium, the ability to extrude PB1 was quickly restored and a $72.1 \%$ IE rate was obtained following such treatment. These results demonstrate that demecolcine can be used as a potential reagent for induced enucleation of sheep meiotically maturing oocytes and may greatly facilitate research in nuclear transfer.
\end{abstract}

enucleation / oocyte / sheep / demecolcine / meiosis / nuclear transfer

\section{INTRODUCTION}

Although the technology of animal cloning by nuclear transfer of a somatic cell into an enucleated oocyte has been successfully applied in several mammalian species, its efficiency still remains low [1]. Many steps of nuclear transfer need to be improved including enucleating recipient oocytes [2]. Traditionally, enucleation is done mechanically by aspirating a large volume of cytoplasm containing chromosome associated with the first polar body (PB1) from the matured metaphase M II oocytes. However,

\footnotetext{
* Corresponding author: xra@cau.edu.cn
} 
this method may result in excess loss of cytoplasm and severe cytoarchitecture damage. Chemical enucleation, induced by treating the oocyte with reagents that disrupt spindle function and chromosome segregation during PB extrusion, might overcome these problems [2]. In most published studies so far the matured oocytes that arrest at M II phase were also chosen for induced enucleation (IE) [3-8] or chemically assisted enucleation [9-11]. For the oocytes in the meiotic phase, induced enucleation may be performed during PB1 extrusion. A previous study [12] showed that treatment of mouse M oocytes with etoposide (ETO), a topoisomerase II inhibitor, and cycloheximide (CHX), a protein synthesis inhibitor yields chemically enucleated cytoplasts at high rates. But enucleated oocytes induced by ETO-CHX or ETO alone have limited ability to support development of the reconstructed embryos [13, 14].

As an alternative to ETO, demecolcine, a microtubule disrupting agent, has been widely used to chemically enucleate M II oocytes in several species [3-9] and cloned offspring produced by this protocol have been reported in mice [8]. As a modified approach, demecolcine-assisted enucleation has also been successfully applied to the production of cloned pigs [10,11]. However, the effectiveness of this reagent for enucleating an oocyte during meiotic maturation, has not been demonstrated. Because the in vitro-maturation of oocytes is frequently used in nuclear transfer procedure of sheep and other domestic animals, it would be desirable to chemically induce the enucleation of the meiotically maturing oocytes.

In the present study, our aims were to investigate the possible effect of demecolcine on induced enucleation of sheep oocytes during maturation in vitro. The optimal conditions of demecolcine treatment for disrupting the spindle function and chemically enucleating the oocytes were examined.

\section{MATERIALS AND METHODS}

\subsection{Chemicals and materials}

Dishes for oocyte culture were purchased from Corning/Coster Company (NY, USA), and all chemicals were purchased from Sigma (St. Louis, MO, USA) unless otherwise indicated.

\subsection{Oocyte collection and maturation in vitro}

Sheep ovaries were collected from a local slaughterhouse and transported to the laboratory within $2 \mathrm{~h}$ in a thermos containing physiological saline at $30^{\circ} \mathrm{C}$. Cumulusoocyte complexes (COC) were recovered by aspiration of follicles 2 to $5 \mathrm{~mm}$ in diameter. The oocytes with evenly granulated cytoplasm and enclosed by more than 3 layers of cumulus cells were selected and washed three times in maturation medium TCM199 (Gibco BRL, Grand Island, NY, USA) supplemented with $20 \%$ estrual sheep serum (made by this lab), $10 \mu \mathrm{g} \cdot \mathrm{mL}^{-1} \mathrm{FSH}$ (Vetrepharm, Canada), $10 \mu \mathrm{g} \cdot \mathrm{mL}^{-1} \mathrm{LH}$ (Bioniche, Canada) and $1 \mu \mathrm{g} \cdot \mathrm{mL}^{-1} 17-\beta$ estradiol. A group of 15 to $20 \mathrm{COC}$ were then transferred into $50 \mu \mathrm{L}$ drops of maturation medium covered with mineral oil and cultured at $38.5^{\circ} \mathrm{C}$ in $5 \% \mathrm{CO}_{2}$ in humidified air for 20 to $22 \mathrm{~h}$.

\subsection{Oocyte treatment and induced enucleation(IE)}

In experiment 1 , at the onset of maturation, COC were cultured in maturation medium supplemented with demecolcine at various final concentrations $(0.4,0.04,0.02$ and $\left.0.01 \mu \mathrm{g} \cdot \mathrm{mL}^{-1}\right)$. In experiment 2 , at 0,6 , or $12 \mathrm{~h}$ after the onset of maturation, COC were cultured in maturation medium supplemented with $0.04 \mu \mathrm{g} \cdot \mathrm{mL}^{-1}$ demecolcine. In experiment 3 , at $12 \mathrm{~h}$ after the onset of maturation, $\mathrm{COC}$ were cultured in maturation medium containing demecolcine $\left(0.04 \mu \mathrm{g} \cdot \mathrm{mL}^{-1}\right)$ alone or demecolcine and CHX $\left(10 \mu \mathrm{g} \cdot \mathrm{mL}^{-1}\right)$ or demecolcine and 
Table I. PB1 extrusion and enucleation efficiency in the oocytes treated with different concentrations of demecolcine at the onset of maturation.

\begin{tabular}{lccc}
\hline Concentrations $\left(\mu \mathrm{g} \cdot \mathrm{mL}^{-1}\right)$ & No. of oocytes & No. of extruded PB1 $(\%)$ & No. of enucleated $(\%)$ \\
\hline $0($ Control $)$ & 98 & $90(91.8)^{\mathrm{a}}$ & - \\
0.4 & 138 & $68(49.3)^{\mathrm{b}}$ & $62(44.9)^{\mathrm{a}}$ \\
0.04 & 136 & $88(65.1)^{\mathrm{c}}$ & $79(58.1)^{\mathrm{b}}$ \\
0.02 & 132 & $111(84.1)^{\mathrm{a}}$ & $30(22.7)^{\mathrm{c}}$ \\
0.01 & 98 & $88(89.8)^{\mathrm{a}}$ & 0 \\
\hline
\end{tabular}

$\mathrm{a,b,c}$ Values with different superscripts within the same column differ significantly $(P<0.05)$.

6-DMAP $(2 \mathrm{mM})$. In experiment 4 , $0.04 \mu \mathrm{g} \cdot \mathrm{mL}^{-1}$ of demecolcine was applied $12 \mathrm{~h}$ after the onset of maturation, then demecolcine-cultured COC were divided into two groups at $18 \mathrm{~h}$ after the onset of maturation, with one group remaining in demecolcine containing medium, and another group being transferred into demecolcinefree medium. In each experiment, the cultured oocytes without any demecolcine treatment were used as controls.

The demecolcine-induced enucleation of the cultured oocytes was evaluated after 20 to $22 \mathrm{~h}$ of culture. The cumulus cells were removed by repeated pipetting in $0.2 \%$ hyaluronidase solution. The denuded oocytes were stained in a medium containing $5 \mu \mathrm{g} \cdot \mathrm{mL}^{-1}$ Hoechest 33342 for $15 \mathrm{~min}$ and then examined under an inverted epifluorescence microscope with a filter selective for Hoechest 33342. The oocytes in which all chromosomes were expelled into the PB1 were considered as successfully enucleated oocytes.

\subsection{Immunocytochemistry analysis}

In order to examine the inhibiting effects of demecolcine on meiotic spindle formation, the cultured oocytes from different treatments were fixed in $4 \%$ paraformaldehyde in PBS for 12 to $14 \mathrm{~h}$ at $4{ }^{\circ} \mathrm{C}$ and in microtubule-stabilizing buffer $(0.1 \mathrm{M}$ Pipes, $5 \mathrm{mM} \mathrm{MgCl}{ }_{2} 6 \mathrm{H}_{2} \mathrm{O}, 2.5 \mathrm{mM}$ EGTA, and $1 \mathrm{mM}$ dithiothreitol) for $1 \mathrm{~h}$ at $37^{\circ} \mathrm{C}$. Fixed oocytes were blocked in PBS containing 3\% BSA, $0.2 \%$ Triton X-100 until processing for immunocytochemistry. The oocytes were incubated with fluorescein isothiocyanate-conjugated anti- $\alpha$-tubulin antibody (final dilution, 1:100) for $2 \mathrm{~h}$ at $37^{\circ} \mathrm{C}$. After being washed several times in PBS containing $0.3 \% \mathrm{BSA}$, the oocytes were incubated at $37^{\circ} \mathrm{C}$ for $20 \mathrm{~min}$ in $20 \mu \mathrm{g} \cdot \mathrm{mL}^{-1}$ propidium iodide for DNA staining.

Observations were performed with a confocal laser scanning ultraview microscope (Bio-Rad MRC 1024ES) with excitation wavelengths of 488 and $568 \mathrm{~nm}$. All processed images were assembled and merged with Confocal Assistant software.

\subsection{Statistical analysis}

Data were analyzed by chi-square test. A probability value of $P<0.05$ was considered to be statistically significant.

\section{RESULTS}

After culture in the maturation medium supplemented with different concentrations of demecolcine (ranging from 0.01 to $0.4 \mu \mathrm{g} \cdot \mathrm{mL}^{-1}$ ) for $20-22 \mathrm{~h}$, the spindle function and PB1 extrusion of the oocytes were affected in a dose-dependent manner as shown in Table I. High concentrations of demecolcine $\left(0.04\right.$ to $\left.0.4 \mu \mathrm{g} \cdot \mathrm{mL}^{-1}\right)$ effectively disrupted the meiotic spindle function and produced higher proportions of enucleated oocytes $(44.9 \%$ to $58.1 \%)$, but PB1 extrusion was strongly inhibited when the oocytes were treated with demecolcine at these concentrations. The highest IE rate $(58.1 \%, P<0.05)$ resulted from the treatment 

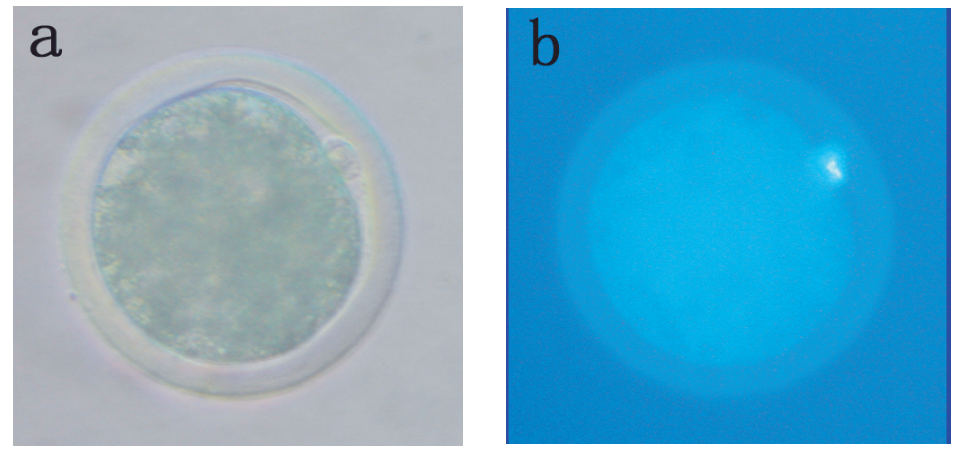

Figure 1. Demecolcine induced enucleation of a sheep oocyte. The oocyte was cultured for $20 \mathrm{~h}$ in the maturation medium containing $0.04 \mu \mathrm{g} \cdot \mathrm{mL}^{-1}$ demecolcine at the onset of maturation. (a) The extruded first polar body of the oocyte was observed visible under brightfield microscopy. (b) The same oocyte was assessed under an ultraviolet light field after staining with Hoechest 33342. Note that all stained chromosomes were expelled inside the first polar body.

Table II. PB 1 extrusion and enucleation efficiency in the oocytes treated with $0.04 \mu \mathrm{g} \cdot \mathrm{mL}^{-1}$ demecolcine at different times after the onset of maturation.

\begin{tabular}{lccc}
\hline Treatment* & No. of oocytes & No. of extruded PB1 $(\%)$ & No. of enucleated $(\%)$ \\
\hline Control & 71 & $62(82.7)^{\mathrm{a}}$ & - \\
$0 \mathrm{~h}$ & 75 & $48(64.0)^{\mathrm{b}}$ & $42(56.0)^{\mathrm{a}}$ \\
$6 \mathrm{~h}$ & 84 & $51(60.7)^{\mathrm{b}}$ & $48(57.1)^{\mathrm{a}}$ \\
$12 \mathrm{~h}$ & 96 & $64(66.7)^{\mathrm{b}}$ & $56(58.3)^{\mathrm{a}}$ \\
\hline
\end{tabular}

${ }^{*}$ The demecolcine treatment was applied 0,6 and $12 \mathrm{~h}$ after the onset of maturation, respectively.

a, b Values with different superscripts within the same column differ significantly $(P<0.05)$.

at $0.04 \mu \mathrm{g} \cdot \mathrm{mL}^{-1}$ demecolcine (Fig. 1), although chromosome mass was less condensed and more microtubule remnants were observed in the oocyte treated with demecolcine at this concentration than that with $0.4 \mu \mathrm{g} \cdot \mathrm{mL}^{-1}$ demecolcine (data not shown).

As shown in Table II, when the oocytes were treated with $0.04 \mu \mathrm{g} \cdot \mathrm{mL}^{-1}$ demecolcine $6 \mathrm{~h}$ or $12 \mathrm{~h}$ after the onset of maturation, the PB1 extrusion rate and IE efficiency were not significantly different from those treated at the onset of maturation $(P>0.05)$. As shown in Figure 2, after $12 \mathrm{~h}$ of maturation culture, the typical meiotic spindles formed in untreated oocytes (Fig. 2a), whereas the spindles were not organized in stage-matched oocytes treated with demecolcine (Fig. 2b). When demecolcine application was initiated $12 \mathrm{~h}$ after the onset of maturation, the spindle microtubules were partially disorganized and the arrangement of chromosomes became irregular when analyzed after $3 \mathrm{~h}$ of treatment (Fig. 2d), while in stage-matched untreated oocytes, the spindle elongation and chromosomes segregation were observed in $40 \%$ of the examined oocytes (Fig. 2c). At $18 \mathrm{~h}$ after the onset of maturation, chromosomes and spindles at telophase-I were observed in untreated oocyte (Fig. 2e), while in demecolcine-treated oocytes, all chromosomes joined together and approximated to the cortex of the oocytes (not shown) or presented in the polar body protrusions (Fig. 2f).

Treatment of $\mathrm{M}$ oocytes with demecolcine combined with $\mathrm{CHX}$ or 6-DMAP strongly inhibited the PB1 extrusion (Tab. III). When these oocytes were examined at 20 to 

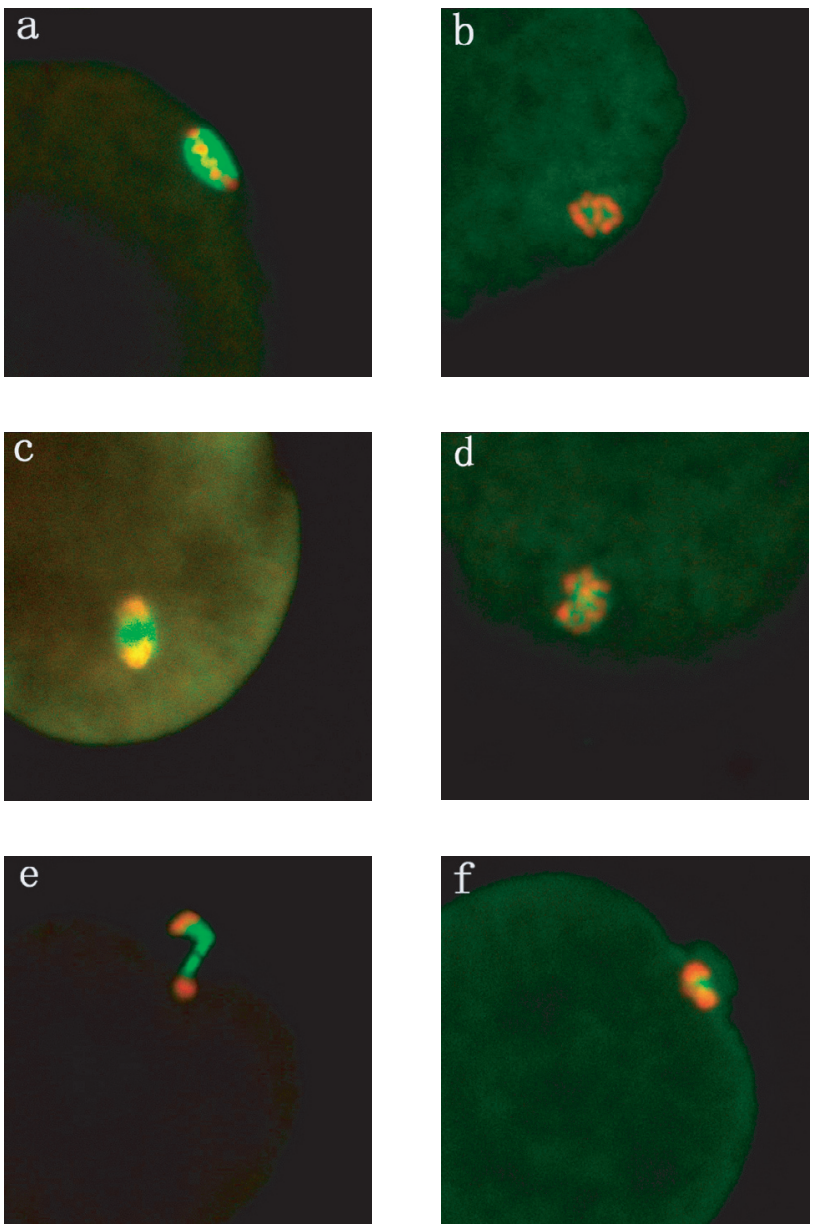

Figure 2. Confocal observations of spindle status of control and demecolcine-treated oocytes. Cultured sheep oocytes were fixed at different time points and microtubules were immunostained with fluorescein isothiocyanate-conjugated antitubulin antibodies (green), and were DNA stained with propidium iodide (red). Control oocytes were fixed at $12 \mathrm{~h}(\mathbf{a})$, $15 \mathrm{~h}(\mathbf{c})$ or $18 \mathrm{~h} \mathrm{(e)} \mathrm{after} \mathrm{the}$ onset of maturation. A normal meiotic pattern with the organized spindle (a), elongated spindle (c) and separated spindle (e) were observed. Stained oocytes treated with demecolcine $\left(0.04 \mu \mathrm{g} \cdot \mathrm{mL}^{-1}\right)$ are shown as $(\mathbf{b}),(\mathbf{d})$ and (f). The spindle was not observed in the oocyte treated with demecolcine at the onset of maturation and fixed at $12 \mathrm{~h}$ after the onset of maturation (b). The meiotic spindle was partially disorganized in the oocytes treated with demecolcine $12 \mathrm{~h}$ after the onset of maturation and fixed at $15 \mathrm{~h}$ after the onset of maturation (d). In the oocyte treated with demecolcine $12 \mathrm{~h}$ after the onset of maturation and fixed at $18 \mathrm{~h}$ after the onset of maturation, the chromosomes joined together and presented in the protruded polar body $(\mathbf{f})$.

Table III. Effects of combination treatment of sheep M I oocytes with demecolcine and cycloheximide or 6-DMAP on PB1 extrusion and chromosome status.

\begin{tabular}{lccc}
\hline Treatment* & No. of oocytes & $\begin{array}{c}\text { No. of extruded } \\
\text { PB1 }(\%)\end{array}$ & $\begin{array}{c}\text { Status of unextruded } \\
\text { chromosomes }\end{array}$ \\
\hline Control & 75 & $61(81.3)^{\mathrm{a}}$ & Condensed \\
DMC & 70 & $35(50.0)^{\mathrm{b}}$ & Condensed \\
DMC+CHX & 80 & $8(10.0)^{\mathrm{c}}$ & Decondensed or pronuclear formed \\
DMC+DMAP & 80 & $5(6.0)^{\mathrm{c}}$ & Decondensed or pronuclear formed \\
\hline
\end{tabular}

* At $12 \mathrm{~h}$ after the onset of maturation, the oocytes were treated with demecolcine alone $\left(0.04 \mu \mathrm{g} \cdot \mathrm{mL}^{-1}\right)$ (DMC group), or combined with cycloheximide $\left(10 \mu \mathrm{g} \cdot \mathrm{mL}^{-1}\right)(\mathrm{DMC}+\mathrm{CHX}$ group) or 6-dimethylaminopurine (2 mM) (DMC + DMAP group).

a,b,c Values with different superscripts within the same column differ significantly $(P<0.05)$. 
Table IV. PB1 extrusion and enucleation efficiency in the treated oocytes after the withdrawal of demecolcine.

\begin{tabular}{lcccc}
\hline Treatment* & No. of oocytes & $\begin{array}{c}\text { No. of extruded } \\
\text { PB1 }(\%)\end{array}$ & \multicolumn{2}{c}{ Rates of enulceation \% } \\
\cline { 4 - 5 } & & $\begin{array}{c}\text { Based on } \\
\text { total oocyte }\end{array}$ & $\begin{array}{c}\text { Based on the oocytes } \\
\text { with PB1 }\end{array}$ \\
\hline Control & 60 & $53(88.3)^{\mathrm{a}}$ & - & - \\
DMC & 56 & $35(62.5)^{\mathrm{b}}$ & $57.1(32 / 56)^{\mathrm{a}}$ & $91.4(32 / 35)^{\mathrm{a}}$ \\
DMC to normal & 104 & $93(89.4)^{\mathrm{a}}$ & $72.1(75 / 104)^{\mathrm{b}}$ & $80.6(75 / 93)^{\mathrm{b}}$ \\
\hline
\end{tabular}

* Demecolcine $\left(0.04 \mu \mathrm{g} \cdot \mathrm{mL}^{-1}\right)$ was applied $12 \mathrm{~h}$ after the onset of maturation. A group of treated oocytes were transferred into demecolcine-free medium $18 \mathrm{~h}$ after the onset of maturation (DMC to normal group), while another group of oocytes retained in demecolcine-containing medium (DMC group). PB1 extrusion and induced enucleation were evaluated $20-22 \mathrm{~h}$ after the onset of maturation.

a,b Values with different superscripts within the same column differ significantly $(P<0.05)$.

$22 \mathrm{~h}$ after the onset of maturation, the unextruded chromosomes displayed a decondensed or pronuclear-like structure, while the unextruded chromosomes in the oocytes treated with demecolcine alone remained in a condensed form.

At $18 \mathrm{~h}$ after the onset of maturation, PB1 extrusion occurred in above $80 \%$ of untreated oocytes, but in $50 \%$ of those demecolcine-treated (data not shown). Prolonged maturation did not lead to a significant increase of PB1 extrusion rate in the treated oocytes. However, when the demecolcine-treated oocytes were transferred to the normal medium at $18 \mathrm{~h}$ after the onset of maturation and further cultured for 2-4 h , they extruded PB1 at a similar rate to the control group (89.4\% vs. 88.3, $P>0.05)$. An overall IE efficiency of $72.1 \%$ was obtained, significantly higher than that from the oocytes retained in demecolcine-containing medium $(72.1 \%$ vs. $57.1 \%, P<0.05$ ), as shown in Table IV.

\section{DISCUSSION}

Previous studies have shown that induced enucleation performed during meiosis II could be achieved by a brief exposure of the pre-activated oocytes to demecolcine [3-9]. The current study tested the effects of demecolcine treatment, the long duration relative to that applied during meiosis II, on the process of meiosis I and therefore the possibility of induced enucleation.

As the present study shows, meiosis resumption could occur in sheep GV oocytes that were cultured in the presence of demecolcine, as characterized by GVBD and chromosome condensation, although the meiotic spindle did not form. A similar phenomenon was also observed in nocodazole-treated porcine GV oocytes [15]. However in that study, it was shown that the PB1 extrusion was completely blocked after treatment with nocodazole [15]. But our results showed that the PB1 could be extruded in the oocytes even treated with higher concentrations of demecolcine, though at lower rates than those untreated ones or treated with lower concentrations. As a result of disruption of the spindle function, in approximately $90 \%$ of the oocytes that completed cytokinesis, all chromosomes were expelled into the extruded polar bodies and enucleated cytoplasts were generated.

We observed in our study that during in vitro maturation, GVBD of sheep oocytes occurred $6 \mathrm{~h}$ after the onset of maturation and $\mathrm{M}$ spindle formed $12 \mathrm{~h}$ after the onset of maturation. Studies by Fulka and Moor showed that ETO treatment at the M phase resulted in better enucleation [12]. Our study examined whether demecolcine still played an inhibitory role on spindle function and PB 1 extrusion when demecolcine treatment was applied after GVBD occurs and 
the meiotic spindle forms. It is not surprising that delaying the addition of demecolcine up to 6 or $12 \mathrm{~h}$ after the onset of oocyte maturation yielded similar results to that treated at the onset of maturation, because both spindle microtubules and nonspindle microtubules were disrupted by demecolcine. We also observed at $15 \mathrm{~h}$ after the onset of maturation that about $40 \%$ of the examined sheep oocytes were in transition from metaphase to anaphase or telophase, with the occurrence of chromosome segregation. It was suggested that the extent of chromatid segregation is a key determinant of enucleation [5]. For this reason, we suggest the demecolcine treatment should be applied not later than $12 \mathrm{~h}$ after the onset of maturation, if sheep $M$ oocytes were used to induce enucleation.

Previous studies with mouse M II oocytes revealed that the impairment of $\mathrm{PB}$ extrusion was the chief limitation to induced enucleation $[5,8]$. A similar situation was also observed in our study with M I oocytes. The reason for this is still unknown. It has been well established that an intact microtubule spindle is required for the maturation-promoting factor (MPF) inactivation and thus cell cycle exit from the arrest at the M II phase [16, 17], but little information in this regard is known in the oocytes during meiosis I. CHX, a protein synthesis inhibitor and 6-DMAP, a protein kinase inhibitor were frequently used to artificially reduce the MPF activity which is at peak level at the $\mathrm{M}$ phase, and is responsible for oocyte arrested at this stage. CHX treatment facilitates the PB1 extrusion of ETO-treated mouse $\mathrm{M}$ oocytes via a reduced MPF level $[12,18]$. In contrast, demecolcine treatment combined with CHX or 6-DMAP led to a nuclear formation rather than $\mathrm{PB}$ extrusion in the present study. This result implies that the decline of MPF activity is not sufficient for PB formation, inconsistent with studies on ETO-induced enucleation [12, 18, 19].

Nevertheless, we found that demecolcine-inhibited PB1 extrusion was reversibly restored within a short time when the treated oocytes were placed back into a demecolcine-free medium. Chemically induced enucleation still occurred in approximately $80 \%$ of the PB1-extruded oocytes following such medium alteration. By immunofluorescent staining, we observed that the microtubules were re-assembled to a large extent after demecolcine was withdrawn (unpublished data). But in a majority of cases, these spindle microtubules may have not gained a function before the completion of PB1 formation, thus these microtubules together with chromosomes were expelled into PB1. Cases of spontaneous PB refusion with the cytoplasts have been observed in ETO-treated mouse M oocytes [13] and have been more frequently observed in demecolcine-treated M II oocytes [5, 8]. In our study, however, further culture of the treated oocytes for $9 \mathrm{~h}$ after the withdrawal of demecolcine did not result in a decrease in PB1 extrusion rate when compared to that scored at $4 \mathrm{~h}$ after the withdrawal of demecolcine (unpublished data). In fact, we observed that PB1 in sheep oocytes seemed subject to become degenerated or fragmented after the cumulus cells were removed by pipetting, therefore without a trend to refuse with the cytoplasts. In these cases, the enucleation was permanent.

In summary, the results of the present study suggest that demecolcine can be used as a potential reagent for induced enucleation of sheep oocytes in meiosis I. This simple approach may provide a new enucleation method to prepare cytoplasts for nuclear transfer. However, its final utility requires further confirmation in nuclear transfer experiments.

\section{ACKNOWLEDGMENTS}

The authors thank Drs Zhou Huanmin and Li Jinquan (Inner Mongolian Agricultural University) for kindly providing their labs to complete a part of this work. We are grateful to Dr Robert Foote (Cornell University) for revising the English version of the manuscript. This research was supported by the research project of High-Tech 
Research and Development Program of China (2002AA206311) and a competitive research grant from the Natural Scientific Foundation of China (30270956)

\section{REFERENCES}

[1] Campbell KHS, Alberio R, Choi I, Fisher P, Kelly RDW, Lee JH, Maalouf W. Cloning: eight years after Dolly. Reprod Dom Anim 2005, 40: 256-268.

[2] Fulka J Jr, Loi P, Fulka H, Ptak G, Nagai T. Nucleus transfer in mammals: noninvasive approaches for the preparation of cytoplasts. Trends Biotech 2004, 22: 279-283.

[3] Baguisi A, Overström EW. Induced enucleation in nuclear transfer procedures to produce cloned animals. Theriogenology 2000, 54: 209.

[4] Ibáñez E, Sanfins A, Combelles C, Albertini DF, Overström EW. Induced enucleation of mouse and goat oocytes: kinetic and phenotypic characterizations. Theriogenology 2002, 57: 421.

[5] Ibáñez E, Albertini DF, Overström EW. Demecolcine-induced oocyte enucleation for somatic cell cloning: coordination between cell-cycle egress, kinetics of cortical cytoskeletal interactions, and second polar body extrusion. Biol Reprod 2003, 68: 1249-1258.

[6] Fischer D, Ibáñez E, Cibelli J, Albertini DF, Overström EW. Activated bovine cytoplasts produced by induced enucleation support development of bovine nuclear transfer embryos in vitro. Biol Reprod 2002, 66 (Suppl 1): 238.

[7] Gasparrini B, Dinnyes A, Ainslie A, Marshall C, Ritchie WA, Travers A, Wilmut I, De Sousa PA. Attempted chemical enucleation of in vitro matured sheep oocytes after activation and their use in nuclear transfer. Theriogenology 2002, 57: 414 .

[8] Gasparrini B, Gao S, Ainslie A, Fletcher J, McGarry M, Ritchie WA, Springbett AJ, Overström EW, Wilmut I, De Sousa PA. Cloned mice derived from embryonic stem cell karyoplasts and activated cytoplasts prepared by induced enucleation. Biol Reprod 2003, 68: 1259-1266.

[9] Yin XJ, Kato Y, Tsunoda Y. Effect of enucleation procedures and maturation conditions on the development of nuclear-transferred rabbit oocytes receiving male fibroblast cells. Reproduction 2002, 124: 41-47.

[10] Yin XJ, Tani T, Yonemura I, Kawakami M, Miyamoto K, Hasegawa R, Kato Y, Tsunoda Y. Production of cloned pigs from adult somatic cells by chemically assisted removal of maternal chromosomes1. Biol Reprod 2002, 67: 442-446.

[11] Kawakami M, Tani T, Yabuuchi A, Kobayashi T, Murakami H, Fujimura T, Kato Y, Tsunoda Y. Effect of demecolcine and nocodazole on the efficiency of chemically assisted removal of chromosomes and the developmental potential of nuclear transferred porcine oocytes. Cloning and Stem Cells 2003, 5: 379-387.

[12] Fulka J Jr, Moor RM. Noninvasive chemical enucleation of mouse oocytes. Mol Reprod Dev 1993, 34: 427-30.

[13] Elsheikh AS, Takahashi Y, Hishinuma M, Kanagawa H. Developmental ability of mouse late 2-cell stage blastomeres fused to chemically enucleated oocytes in vitro. J Vet Med Sci 1997, 59: 107-13.

[14] Elsheikh AS, Takahashi Y, Katagiri S, Kanagawa $\mathrm{H}$. Functional enucleation of mouse metaphase II oocytes with etoposide. Jpn J Vet Res 1998, 45: 217-220.

[15] Sun QY, Lai L, Park KW, Kühholzer B, Prather RS, Schatten H. Dynamic events are differently mediated by microfilaments, microtubules, and mitogen-activated protein kinase during porcine oocyte maturation and fertilization in vitro. Biol. Reprod 2001, 64: 879-889.

[16] Kubiak JZ, Weber M, Pennart H, Winston NJ, Maro B. The metaphase II arrest in mouse oocytes is controlled through microtubuledependent destruction of cyclin B in the presence of CSF. EMBO J 1993, 12: 3773-3778.

[17] Winston N, McGuinness O, Johnson MH, Maro B. The exit of mouse oocytes from meiotic M-phase requires an intact spindle during intracellular calcium release. J Cell Sci 1995, 108: 143-151.

[18] Fulka J Jr, Moor RM, Fulka J. Sister chromatid separation and the metaphase-anaphase transition in mouse oocytes. Dev Biol 1994, 165: 410-417.

[19] Karnikova L, Horska M, Tomanek M, Kanka J, Urban F, Moor R, Fulka J Jr. Chemically enucleated mouse oocytes: ultrastructure and kinetics of histone H1 kinase activity. Reprod Nutr Dev 1998, 38: 643-51. 